\title{
Aquatic Diptera (Insecta) assemblages in four sympatric Eryngium (Apiaceae) phytotelmata in flowering and senescent times
}

\author{
Raúl Ernesto Campos
}

Instituto de Limnología 'Dr Raúl A. Ringuelet', Universidad Nacional de La Plata - Consejo Nacional de Investigaciones Científicas y Técnicas, CCT La Plata, Boulevard 120 and 62, CC 712 (1900) La Plata, Buenos Aires, Argentina

\begin{abstract}
This study addresses how Diptera assemblages differ in four sympatric phytotelmata. The Eryngium species retain water in their axils forming a phytotelm and this situation leads to the speculation that dipteran assemblages may differ, mainly when the plants begin to grow and retain more water in their axils, and when becoming senescent. Diptera from Eryngium horridum, Eryngium stenophyllum, Eryngium aff. serra and Eryngium elegans were sampled. This study revealed that the Eryngium spp. are used by Diptera differentially and their populations show seasonal changes, with peaks in the autumn. Diptera were represented by immature stages belonging to six aquatic and seven semi-aquatic families. The most important were Chironomidae, Culicidae, Periscelididae and Ceratopogonidae. Two species of Chironomids were the most abundant. Culicidae, Periscelididae and Ceratopogonidae were more selective than Chironomidae. Saprophages were the most abundant where the fine detritus feeders were the dominant group. Periscelididae was the main free-swimming predator.
\end{abstract}

\section{ARTICLE HISTORY}

Received 26 June 2014

Accepted 2 September 2015

Online 7 October 2015

\section{KEYWORDS}

Biodiversity;

Ceratopogonidae;

Chironomidae; Culicidae; seasonality; Periscelididae

\section{Introduction}

Phytotelmata are puddles retained in terrestrial and epiphytic plants, which harbour many species of invertebrates and small vertebrates. The most common and studied phytotelmata are tree holes, bamboo internodes, leaf axils of Bromeliaceae and pitcherplants (Frank and Lounibos 1983); however, it is known that more than 1500 species of plants provide suitable habitats where aquatic organisms develop (Fish 1983).

Eryngium L. (Apiaceae) is a cosmopolitan genus of perennial, rhizomatous herbs and terrestrial plants that includes more than 200 species in temperate and tropical regions, of which 31 are known in Argentina (Martínez 2005). However, few species capture and retain water in their leaf axils. Despite the fact that Eryngium plants and bromeliads have a similar physiognomy, their phytotelmata are simpler, lacking the semi-central and central cavities. Water in external cavities is ephemeral and makes favourable habitats 
for semi-aquatic macroinvertebrates. The real cavity containing water for a long time is limited to axils of internal leaves (Campos 2010).

The aquatic fauna occurring in axils of several species of Eryngium from Argentina (Vucetich and Rossi 1980; Campos 2010; Campos and Fernández 2011) and Brazil (Machado 1976) has been inventoried. The taxonomic composition of aquatic and semi-aquatic organisms at the ordinal level revealed that Diptera were the best represented in the Eryngium communities. Nine aquatic and six semi-aquatic families have been reported (Campos 2010 appendix). However, only Culicidae and Chironomidae have been studied; addressing issues such as selective oviposition of Culex castroi Casal and García, (Balseiro 1983); seasonality and population dynamics of three species of Culex in Eryngium pandanifolium Cham. and Schlecht and Eryngium cabrerae Pontiroli (Campos and Lounibos 1999); epizootiology of Amblyospora camposi Micieli, García and Becnel (Microsporidian) in Culex renatoi Lane and Ramalho (Micieli et al. 2007), mosquito species richness in E. pandanifolium, Eryngium serra Cham. and Schltdl. and Eryngium eburneum Decne (Albicócco et al. 2011), and seasonal prevalence of Harpellales (Zygomycota: Trichomycetes) from chironomid larvae (Siri et al. 2008).

The Eryngium species are perennial plants with an annual cycle that wastes the water retained in their axils, when the plant goes into senescence after flowering at the end of the autumn. This situation led to speculation that the dipteran communities inhabiting them may differ in richness of species and abundance, mainly between the spring, when the plants begin to grow and retain more water in their axils, and autumn, when the plants become senescent.

The present study aims to compare the assembly of dipterans, the main taxon that develops, in four sympatric species of Eryngium during temperate seasons, coinciding with the time of flowering and senescence of the host plants. The sample is designed to find most dipteran species that inhabit the leaf axils during the wet spring and dry autumn.

\section{Material and methods}

\section{Study area and phytotelmata species}

Field studies were conducted in 'Ernesto Tornquist' Provincial Park, Sierra de la Ventana $\left(38^{\circ} 10^{\prime} \mathrm{S}, 62^{\circ} 8^{\prime} \mathrm{W}\right)$, situated in the southeast of the Austral Pampean biogeographic district in Buenos Aires Province, Argentina (Cabrera and Willink 1980). This district is characterized by a plain with extensive pastures and a mountain range $170 \mathrm{~km}$ long with a maximum height of $1243 \mathrm{~m}$ above sea level, oriented from northwest to southeast (Harrington 1947). The climate of the mountain range is wet-subwet with a slight deficit of water (Burgos and Vidal 1951). The main rains occur during spring-summer and the drought period is autumn-winter; the winters are severe with occasional snow and a strong annual temperature variation (Kristensen and Frangi 1995). Annual mean temperature and precipitations are $14^{\circ} \mathrm{C}$ and $896 \mathrm{~mm}$, respectively (SMN 1981, 1986).

Four Eryngium species out of seven recognized from Sierra de la Ventana (Frangi and Bottino, 1995) - Eryngium horridum Malme, Eryngium stenophyllum Urb., Eryngium aff. serra Cham. and Schltdl. and Eryngium elegans Cham. and Schltdl. - hold water and debris in their leaf axils (Figure 1). All species are terrestrial, E. horridum and E. stenophyllum occurred in dry and rocky soil, wwhereas $E$. aff. serra 


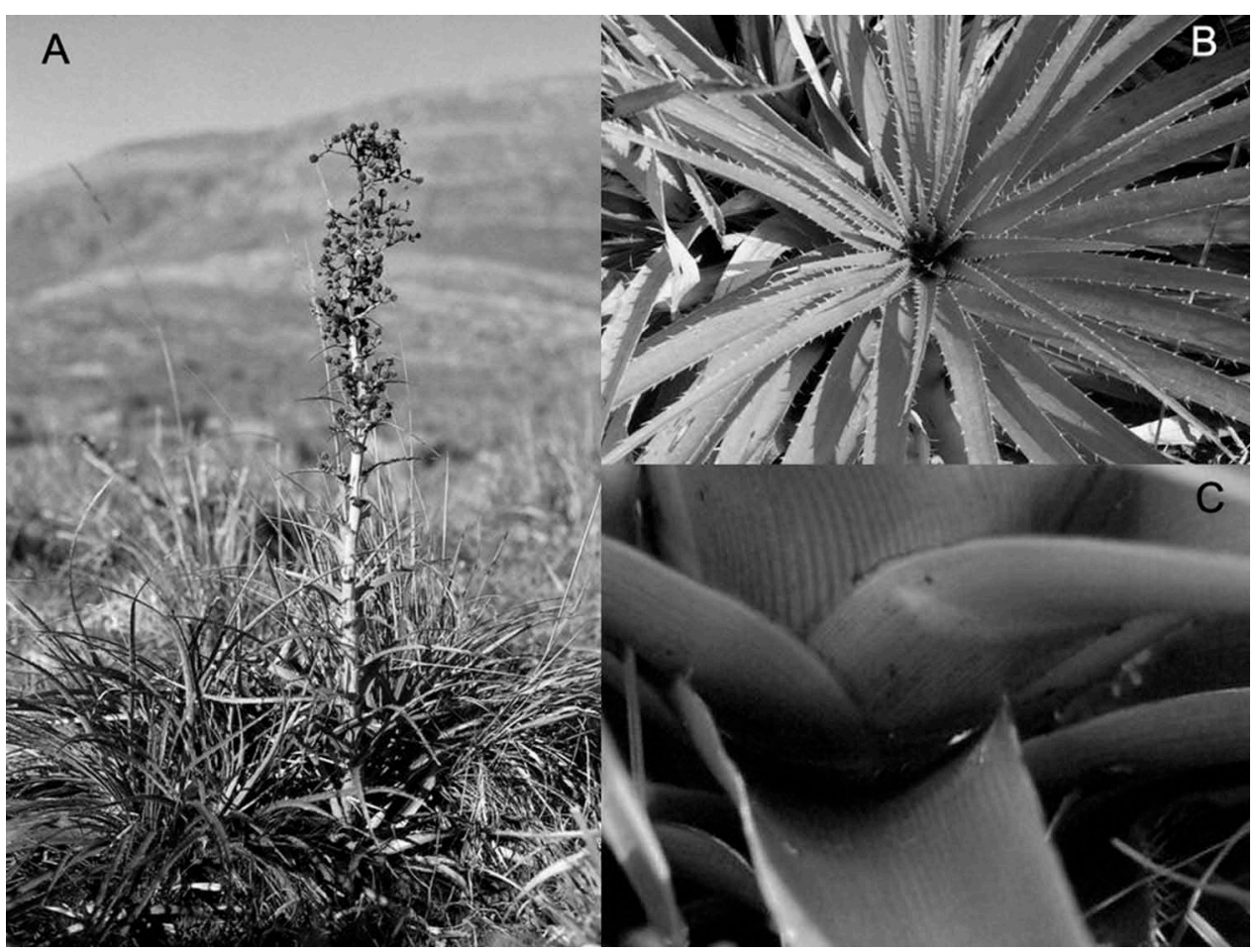

Figure 1. Eryngium horridum: (A) flowering plant; (B) top view of a non-flowering plant showing arrangement of leaves; $(C)$ detail of axils containing water.

and E. elegans grow near the edges of streams, in moist soils and in fields prone to flooding (Campos 2010).

\section{Sampling design and sample extraction}

Forty plants of E. horridum, E. stenophyllum, E. aff. serra and E. elegans were randomly selected and sampled in spring and autumn. Eryngium horridum and E. stenophyllum were sampled from dry, open, sloping terrain, approximately $>20 \mathrm{~m}$ from streams, in 2006, and E. aff. serra and E. elegans were sampled from stream edges and ravines in 2007. All plants were exposed to sunlight because there are no trees in the study area. All samples were taken in the same area; about $500 \mathrm{~m}$ above sea level, in spring (flowering time) and autumn (senescence time). Two species of Eryngium were sampled from the edge of streams and two from $20 \mathrm{~m}$ away from the stream because they naturally grow in those sites. The two species growing on the bank ( $E$. aff. serra and E. elegans) do not grow in areas away from the bank and vice versa. For this study, plants containing water in their axils were studied but no attempts were made to estimate the proportion of plants with or without water.

Fluid contents were extracted with a pipette attached to a lift pump, and subsequently all leaves except the most exterior were removed, from centre to periphery, and washed in a pan to release all adhering organisms; then the cavity formed by the remaining leaves was flushed twice with clean tap water, and the 
aquatic contents were extracted with a pipette after each wash. All organisms were killed in the field and preserved in $80 \%$ commercial ethyl alcohol, except for some individuals of each morpho-species, which were carried alive to the laboratory in individual plastic tubes to be reared and identified. The fluid extracted (original siphoning plus washes) from the plant was observed under a stereo-microscope at $40 \times$ magnification, and the immature dipterans were removed from the debris. Taxonomic resolution was attempted to species level; however, some aquatic larvae have not yet been matched to their adult stage, and unidentifiable species were recorded as morpho-species. Individuals of all taxa were sent to specialists for identification. Taxa for which no specialists were known in Argentina were classified to family following the keys of Stehr (1991).

\section{Data analyses}

To estimate the sample size (number of plants) that quantified the number of taxa inhabiting each phytotelm, cumulative dipterans were plotted and fitted to the best curves. Comparisons between the proportion of Eryngium containing immatures of dipteran families in autumn and spring were tested by $G$-test $\left(G_{\text {adj. }}\right)$. As the data obtained from samples violated the assumption of normality and homogeneity of variances, the non-parametric two-way analysis of variance with Scheirer-Ray-Hare extension (Scheirer et al. 1976; as described in Sokal and Rohlf 1995) was used to determine the main and interactive effects of each variable (season and Eryngium species) on the abundance of chironomid species. Multiple comparisons were performed by Mann-Whitney $U$-tests. In order to compromise between a large overall Type I error, which would arise with an a of 0.05 for each separate test, and a large overall Type II error, which would arise with a strict application of Bonferroni correction (i.e. with an a of $0.05 \times 15^{-1}=0.003$ ), an a of 0.01 in each separate post hoc test was used (Nugues and Bak 2006).

Similarity between the four Eryngium species related to dipteran communities was analysed by cluster analysis, using arithmetic averages and the un-weighted pair-group method. For cluster analysis, the Morisita-Horn index was used because it is not dependent on sample size, and is the index least influenced by species richness (Wolda 1981). The analyses were performed using Bio-Dap software (Magurran 1988).

\section{Results}

\section{Adequacy of sampling}

The evaluation carried out to estimate the total taxa inhabiting each plant species indicated that relationships between number of plants sampled and taxa identified, fitted to logarithmic functions, which demonstrated tendencies to reach a plateau (Figure 2). $R^{2}$ values were $>0.66$ and significant $(p<0.001)$ for all species of plants in autumn and spring, except for $E$. stenophyllum in autumn $\left(R^{2}=0.04 ; p=0.09\right)$ where two plants yielded all the Diptera taxa recorded from this phytotelm. 

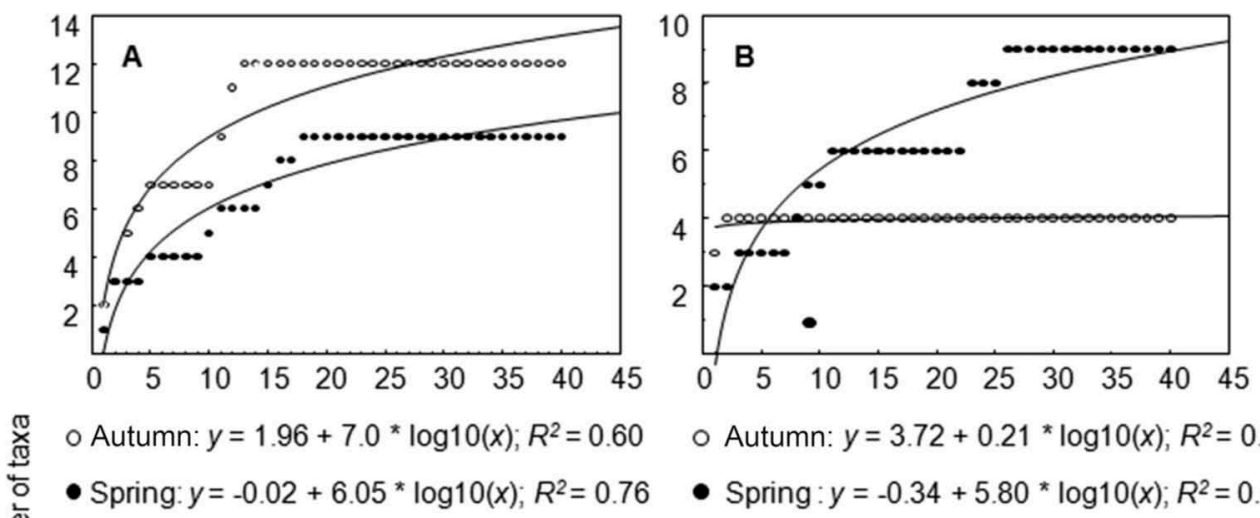

○ Autumn: $y=3.72+0.21{ }^{*} \log 10(x) ; R^{2}=0.04$

- Spring: $y=-0.34+5.80 * \log 10(x) ; R^{2}=0.90$
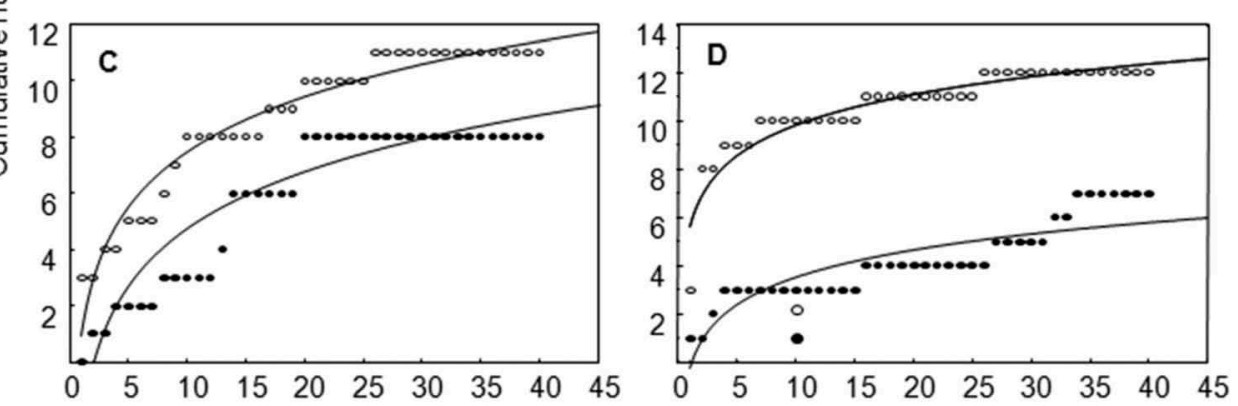

○ Autumn: $y=0.92+6.53{ }^{*} \log 10(x), R^{2}=0.85 \circ$ Autumn: $y=5.58+4.23{ }^{*} \log 10(x) ; R^{2}=0.66$

- Spring: $y=-2.13+6.64{ }^{*} \log 10(x), R^{2}=0.82$

Spring: $y=-0.25+3.76{ }^{*} \log 10(x) ; R^{2}=0.90$

Number of plants sampled

Figure 2. Cumulative total of Diptera observed in successive plants $(n=40$ plants for each species in autumn and in spring). (A) Eryngium horridum; (B) Eryngium stenophyllum; (C) Eryngium aff. serra; (D) Eryngium elegans. Logarithmic equations with $R^{2}$ values; $p<0.001$ for all $R^{2}$ except for E. stenophyllum in autumn $(p=0.09)$.

\section{Community composition and seasonal occurrence of dipterans inhabiting Eryngium phytotelmata}

The community of dipterans that live in the axils of Eryngium consisted of aquatic and semi-aquatic larvae, belonging to six and seven families, respectively (Table 1). Of the 13 families in the community, Chironomidae accounted for $87.6 \%$, followed by Culicidae (3.9\%), Periscelididae (3.4\%) and Ceratopogonidae (3.1\%). The remaining families accounted for $2 \%$.

All E. horridum and E. aff. serra, 37 E. stenophyllum and 39 E. elegans contained larvae of dipterans in autumn, and 38 E. horridum, 40 E. stenophyllum, 37 E. aff. serra and 34 $E$. elegans contained larvae of dipterans in spring. Ten families of dipterans were recorded from E. horridum, all present in autumn, eight of which were also present in spring, except Asilidae and Dolichopodidae. Nine families were present in E. stenophyllum in spring, and only Scatopsidae and Chironomidae in autumn; this was 
Table 1. Taxonomic classification and number of individuals of the aquatic dipterans inhabiting four Eryngium species censused in autumn and spring at Sierra de la Ventana, Argentina.

\begin{tabular}{|c|c|c|c|c|c|c|c|c|}
\hline \multirow[t]{2}{*}{ Taxa } & \multicolumn{2}{|c|}{$\begin{array}{l}\text { Eryngium } \\
\text { horridum }\end{array}$} & \multicolumn{2}{|c|}{$\begin{array}{l}\text { Eryngium } \\
\text { stenophyllum }\end{array}$} & \multicolumn{2}{|c|}{$\begin{array}{l}\text { Eryngium aff. } \\
\text { serra }\end{array}$} & \multicolumn{2}{|c|}{ Eryngium elegans } \\
\hline & Autumn & Spring & Autumn & Spring & Autumn & Spring & Autumn & Spring \\
\hline Tipulidae & & & & & & & 1 & \\
\hline Cecidomyiidae* & 1 & 5 & & 9 & 2 & 7 & 10 & \\
\hline Scatopsidae* & 87 & 39 & 47 & 75 & 13 & 1 & 8 & 7 \\
\hline \multicolumn{9}{|l|}{ Culicidae } \\
\hline Culex castroi & 87 & 29 & & & & & & \\
\hline Culex renatoi & 247 & 514 & & 3 & 22 & & 3 & \\
\hline \multicolumn{9}{|l|}{ Ceratopogonidae } \\
\hline Dasyhelea sp. & & & & & 181 & 48 & 501 & 14 \\
\hline Forcipomyia sp. & & & & & & 1 & & \\
\hline \multicolumn{9}{|l|}{ Chironomidae } \\
\hline Metriocnemus eryngiotelmatus & 1230 & 712 & 2455 & 1393 & 352 & 188 & 860 & 63 \\
\hline $\begin{array}{l}\text { Polypedilum parthenogeneticum } \\
\text { Cricotopus sp. }\end{array}$ & 4990 & 3814 & 64 & 1124 & 1830 & 74 & 1331 & $\begin{array}{r}62 \\
1\end{array}$ \\
\hline Larsia sp. & & & & & 4 & 1 & 28 & 1 \\
\hline Asilidae* & 3 & & & & & & & \\
\hline Dolichopodidae & 4 & & & 22 & & & & 1 \\
\hline Phoridae* & & & & & 1 & & & \\
\hline \multicolumn{9}{|l|}{ Syrphidae } \\
\hline Morpho-species 1 & 17 & 4 & & & & & & \\
\hline Morpho-species 2 & & & & 3 & & & & \\
\hline Tanypezidae* & 3 & 1 & & 12 & 1 & & 2 & \\
\hline Sphaeroceridae* & 25 & 14 & & 3 & & 1 & 3 & 1 \\
\hline Periscelididae: Stenomicra sp. & 460 & 319 & & 4 & 1 & & 3 & \\
\hline Unidentified Diptera* & 4 & & 24 & & 1 & 4 & 3 & \\
\hline
\end{tabular}

*Semi-aquatic.

the only Eryngium where the greatest diversity occurred in spring. In $E$. aff. serra nine families of dipterans occurred, eight in autumn and five in spring. Of the families present in spring, four were also present in autumn, except Spheroceridae. Whereas for E. elegans, 10 families were recorded, nine in autumn and five in spring. Of the families present in spring, four were also present in autumn, except Dolichopodidae (Table 1).

The presence of Chironomid larvae in $70 \%$ and $97.5 \%$ of all the E. horridum, and in $75 \%$ and $97.5 \%$ of all the $E$. elegans in spring and autumn, respectively, indicates a high and significant presence in autumn $(p<0.01)$. Furthermore, the occurrence of ceratopogonid larvae in E. aff. serra and in E. elegans in spring (10\% and $15 \%)$ and in autumn (45\% and 65\%), indicates a significant preference for the latter season in both Eryngium phytotelmata $(p<0.001)$. Sphaeroceridae larvae occurred in more $E$. horridum plants in autumn $(50 \%)$ than in spring $(25 \% ; p<0.05)$. G tests for the other families of dipterans did not significantly support seasonal independence of phytotelmata use (Table 2).

\section{Relevant families of dipterans of the communities inhabiting Eryngium phytotelmata}

\section{Chironomidae}

Four species of Chironomidae were found breeding in the leaf axils of Eryngium, one belonging to the subfamily Chironominae (Polypedilum parthenogeneticum Donato and Paggi) two to Orthocladiinae (Metriocnemus eryngiotelmatus Donato and Paggi, and 
Table 2. G-test results comparing the proportion of Eryngium containing immatures of dipteran families in autumn and spring.

\begin{tabular}{|c|c|c|c|c|c|c|c|c|}
\hline \multirow[t]{2}{*}{ Families } & \multicolumn{2}{|c|}{ E. horridum } & \multicolumn{2}{|c|}{ E. stenophyllum } & \multicolumn{2}{|c|}{ E. aff. serra } & \multicolumn{2}{|c|}{ E. elegans } \\
\hline & $G_{\text {adj }}$ & $\mathrm{P}$ & $G_{\text {adj }}$ & $\mathrm{P}$ & $G_{\text {adj }}$ & $\mathrm{P}$ & $G_{\text {adj }}$ & $\mathrm{P}$ \\
\hline Cecidomyiidae & 0.26 & $>0.70$ & & & 0.18 & $>0.70$ & & \\
\hline Scatopsidae & & & & & 1.69 & $>0.20$ & 0 & $>0.99$ \\
\hline Culicidae & 0.05 & $>0.80$ & & & & & & \\
\hline Ceratopogonidae & & & & & 11.14 & $<0.001$ & 19.79 & $<0.001$ \\
\hline Chironomidae & 10.22 & $<0.01$ & 1.28 & $>0.30$ & 2.65 & $>0.20$ & 7.42 & $<0.01$ \\
\hline Sphaeroceridae & 4.37 & $<0.05$ & & & & & 0.27 & $>0.70$ \\
\hline Periscelididae & 0.27 & $>0.70$ & & & & & & \\
\hline Unident. Diptera & & & & & 0.88 & $>0.50$ & & \\
\hline
\end{tabular}

Families represented by less than 30 individuals and/or lacking in a station, were not tested.

Cricotopus sp.), and a Tanypodinae (Larsia sp.). Metriocnemus eryngiotelmatus and $P$. parthenogeneticum were found in the four species of Eryngium; Larsia sp. in $E$. aff. serra and E. elegans; and Cricotopus sp. in E. elegans. Metriocnemus eryngiotelmatus and $P$. parthenogeneticum were the dominant Chironomidae, Larsia sp. was scarce, and Cricotopus was rare, a single individual being found (Table 1).

Because $M$. eryngiotelmatus and $P$. parthenogeneticum occurred in the four Eryngium species, it was of interest to compare the abundance of both chironomids within phytotelmata and the seasons in which they occurred. The number of larvae of $P$. parthenogeneticum per plant was significantly higher in E. horridum than in the other three phytotelmata $(H=39.37, d f=3, p<0.001$, Figure 3$)$. Whereas for $M$. eryngiotelmatus it was significantly higher in $E$. horridum and $E$. stenophyllum than in $E$. aff. serra and E. elegans $(H=63.39, d f=3, p<0.001$, Figure 4).

The abundance of $P$. parthenogeneticum was affected by seasons, Eryngium phytotelmata and their interaction (Table 3). All Eryngium phytotelmata showed significant differences in the number of individuals of $P$. parthenogeneticum $\left(U_{E \text {. horridum }}=1827\right.$; $p<0.05 ; U_{E \text {. stenophyllum }}=1264.5 ; U_{E \text {. aff. serra }}=2339 ; U_{E \text {. elegans }}=2007 ; n=40 ; p<0.001$ ) being higher in autumn than in spring, except for $E$. stenophyllum where it was the inverse (Table 1). The number of $P$. parthenogeneticum larvae by Eryngium phytotelmata in autumn and spring was significant $\left(H_{\text {Autumn }}=73.90 ; H_{\text {spring }}=28.80 ; d f=3 ; p<0.001\right)$. Paired comparisons for autumn detected significant differences in the number of P. parthenogeneticum larvae for all Eryngium phytotelmata. Whereas for spring, four of six comparisons were significantly different (Table 3 ).

The abundance of $M$. eryngiotelmatus was affected by season, Eryngium phytotelmata and their interaction (Table 4). All Eryngium phytotelmata showed significant differences in the number of individuals of $M$. eryngiotelmatus between autumn and spring $\left(U_{E \text {. horridum }}=1965 ; U_{E \text {. aff. serra }}=2002.5 ; U_{E \text {. elegans }}=2274 ; \mathrm{n}=40 ; p<0.001\right)$, except for $E$. stenophyllum $(U=1808 ; \mathrm{n}=40 ; p>0.05)$. As with $P$. parthenogeneticum, the highest abundance of $M$. eryngiotelmatus occurred in autumn (Table 1). The number of $M$. eryngiotelmatus larvae by Eryngium phytotelmata in autumn and in spring was significant $\left(H_{\text {Autumn }}=23.58 ; H_{\text {Spring }}=32.21 ; d f=3 ; p<0.001\right)$. Significant differences were found in the number of $M$. eryngiotelmatus larvae for four Eryngium phytotelmata comparisons and they were nonsignificant for two, in both, autumn and spring (Table 4). 


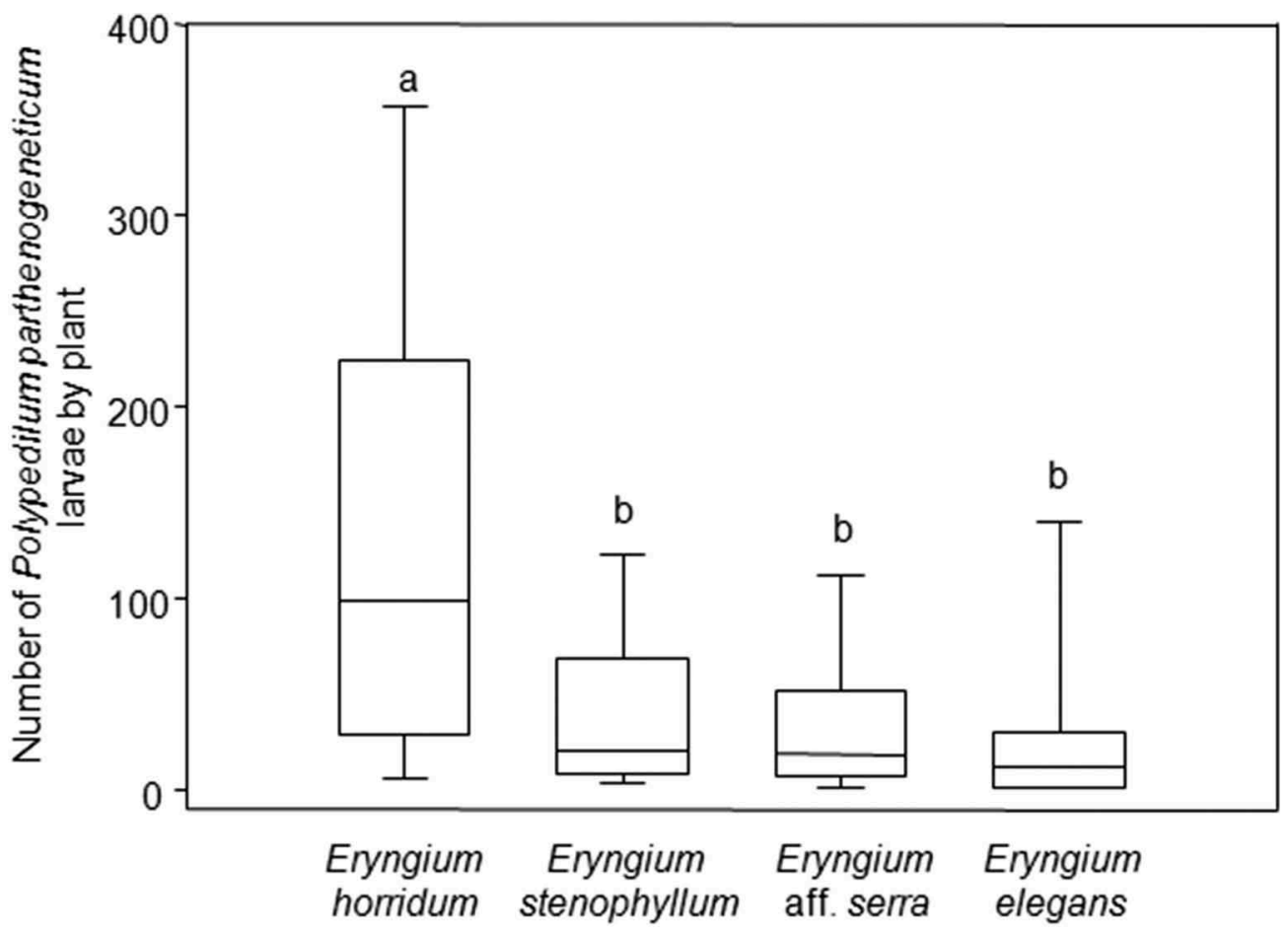

Phytotelmata

Figure 3. Median number of Polypedilum parthenogeneticum larvae per plant in four Eryngium phytotelmata. The box indicates the 25th and 75th centiles, the line within the box indicates the median and the whiskers indicate the 90th and 10th centiles. Different letters indicate significant differences detected by Dunn's test $(p<0.05)$.

Because one plant can be occupied by $P$. parthenogeneticum and $M$. eryngiotelmatus, their co-occurrence in each phytotelmata was analysed. Of all plants containing both species of chironomids, E. horridum was the most relevant. Over $80 \%$ were occupied by both species and $P$. parthenogeneticum was the most abundant species in 49 plants. The occurrence of both species of chironomids was lower in the other three Eryngium species, and $P$. parthenogeneticum was dominant in most plants. In only four plants, both species of chironomids occurred in equal numbers (Table 5). The average number of individuals of $P$. parthenogeneticum per plant, where it was the dominant species, was greater than $M$. eryngiotelmatus in plants where this was the dominant species (except for E. stenophyllum). Conversely, the average number of individuals of $M$. eryngiotelmatus per plant, where it was not the dominant species, was higher than that of $P$. parthenogeneticum in plants where this was not the dominant species (Table 5).

\section{Culicidae}

Two species of mosquitoes were found breeding in Eryngium phytotelmata, Culex castroi Casal and García and Culex renatoi Lane and Ramalho. Culex renatoi occurred 


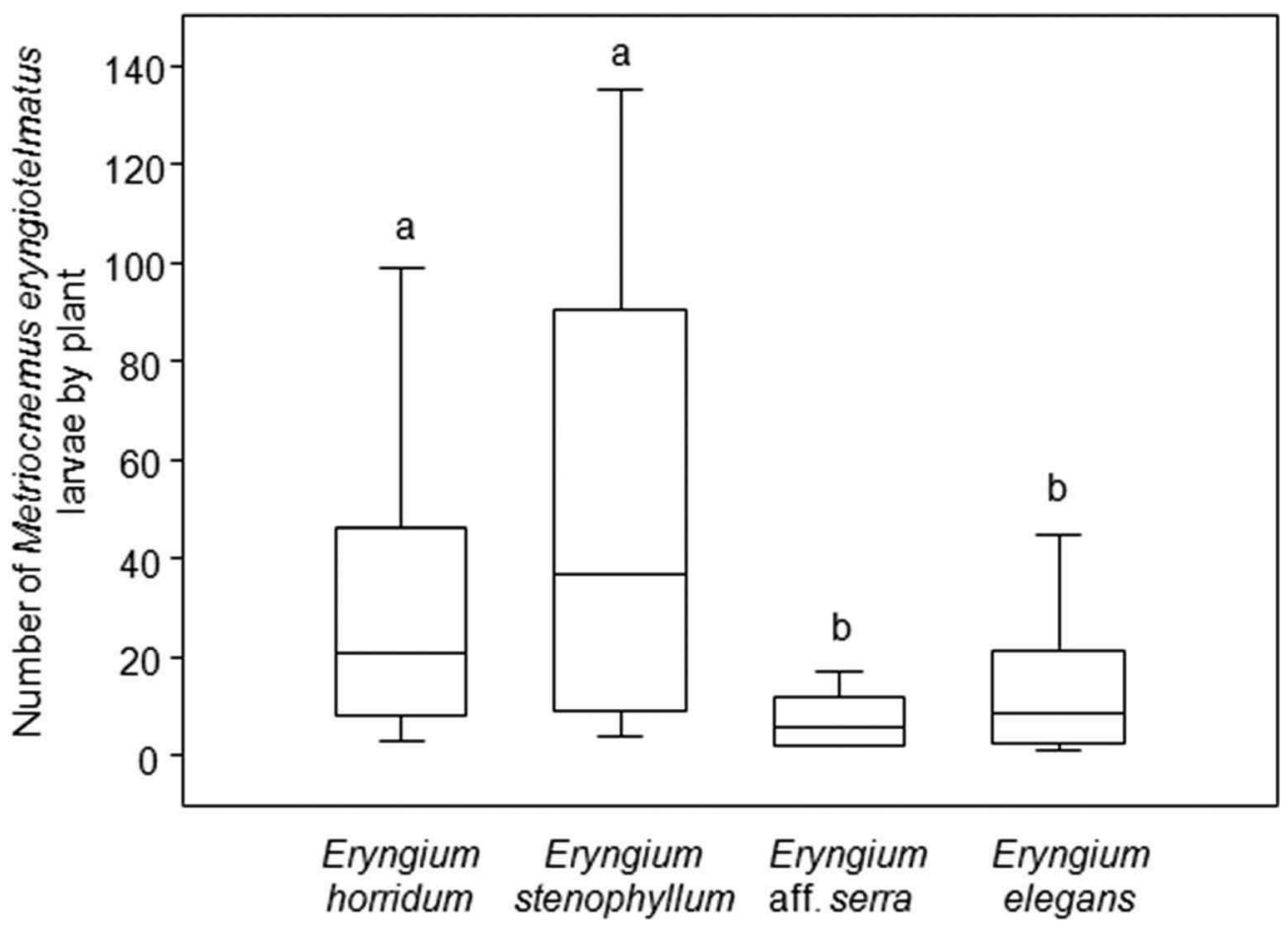

\section{Phytotelmata}

Figure 4. Median number of Metriocnemus eryngiotelmatus larvae per plant in four Eryngium phytotelmata. The box indicates the 25 th and 75 th centiles, the line within the box indicates the median and the whiskers indicate the 90th and 10th centiles. Different letters indicate significant differences detected by Dunn's test $(p<0.05)$.

Table 3. Results of two-way analysis of variance with Scheirer-Ray-Hare extension on the ranks of Polypedilum parthenogeneticum larval abundance by seasons and Eryngium phytotelmata, and posthoc multiple comparisons (pairwise comparisons by Mann-Whitney $U$-test).

\begin{tabular}{|c|c|c|c|c|c|}
\hline Source & df & SS & \multicolumn{2}{|r|}{$\mathrm{SS} / \mathrm{MS}_{\text {Total }}$} & $p$-value \\
\hline Season & 1 & $156,777.778$ & \multicolumn{2}{|r|}{18.315} & $<0.001$ \\
\hline Eryngium & 3 & $421,309.856$ & \multicolumn{2}{|r|}{49.218} & $<0.001$ \\
\hline$S \times E$ & 3 & $411,527.978$ & \multicolumn{2}{|r|}{175.476} & $<0.001$ \\
\hline \multirow{2}{*}{\multicolumn{2}{|c|}{ Comparisons }} & \multicolumn{2}{|c|}{ Autumn } & & Spring \\
\hline & & $U$ & & \multicolumn{2}{|l|}{$U$} \\
\hline \multicolumn{2}{|c|}{ E. horridum - E. stenophyllum } & 2312 & * & 1781.5 & $\mathrm{~ns}$ \\
\hline \multicolumn{2}{|c|}{ E. horridum - E. aff. serra } & 1874 & * & 2007.5 & $*$ \\
\hline \multicolumn{2}{|c|}{ E. horridum - E. elegans } & 2060 & * & 2011 & * \\
\hline \multicolumn{2}{|c|}{ E. stenophyllum - E. aff. serra } & 892.5 & * & 1921.5 & * \\
\hline \multicolumn{2}{|c|}{ E. stenophyllum - E. elegans } & 1187.5 & * & 1927.5 & * \\
\hline \multicolumn{2}{|c|}{ E. aff. serra - E. elegans } & 1951.5 & * & 1622.5 & ns \\
\hline
\end{tabular}

Kruskal-Wallis test showed significant differences among phytotelmata $\left(H_{\text {Autumn }}=73.90 ; H_{\text {Spring }}=28.80 ; d f=3\right.$; $p<0.001) .{ }^{*}=p<0.01$, ns $=$ not significant $(p>0.01)$.

in the four species of Eryngium, but was abundant only in E. horridum where it coexisted with $C$. castroi. The abundance of $C$. renatoi was higher in spring, in contrast to $C$. castroi (Table 1 ). 
Table 4. Results of two-way analysis of variance with Scheirer-Ray-Hare extension on the ranks of Metriocnemus eryngiotelmatus larval abundance by seasons and Eryngium phytotelmata, and post-hoc multiple comparisons (pairwise comparisons by Mann-Whitney U-test).

\begin{tabular}{|c|c|c|c|c|c|}
\hline Source of variation & df & & & $\mathrm{SS} / \mathrm{MS}_{\text {Total }}$ & $p$-value \\
\hline Season & 1 & & & 47.353 & $<0.001$ \\
\hline Eryngium & 3 & & & 36.511 & $<0.001$ \\
\hline$S \times E$ & 3 & & & 10.938 & $<0.02$ \\
\hline \multirow[t]{2}{*}{ Comparisons } & & \multicolumn{2}{|c|}{ Autumn } & \multicolumn{2}{|c|}{ Spring } \\
\hline & \multicolumn{3}{|c|}{$U$} & \multicolumn{2}{|l|}{$U$} \\
\hline \multirow{6}{*}{\multicolumn{2}{|c|}{$\begin{array}{l}\text { E. horridum - E. stenophyllum } \\
\text { E. horridum - E. aff. serra } \\
\text { E. horridum - E. elegans } \\
\text { E. stenophyllum - E. aff. serra } \\
\text { E. stenophyllum - E. elegans } \\
\text { E. aff. serra - E. elegans }\end{array}$}} & 1429 & ns & 1335.5 & * \\
\hline & & 2005.5 & $*$ & 1660.5 & ns \\
\hline & & 1732.5 & ns & 1802 & ns \\
\hline & & 2010 & $*$ & 2041 & $*$ \\
\hline & & 1899.5 & * & 2184 & * \\
\hline & & 1308.5 & * & 1872 & * \\
\hline
\end{tabular}

Kruskal-Wallis test showed significant differences among phytotelmata $\left(H_{\text {Autumn }}=23.58 ; H_{\text {spring }}=32.21 ; d f=3\right.$; $p<0.001){ }^{*}=p<0.01$, ns $=$ not significant $(p>0.01)$.

Table 5. Biological parameters of Eryngium plants where Polypedilum parthenogeneticum and Metriocnemus eryngiotelmatus (Chironomidae) co-occur.

\begin{tabular}{lcccc}
\hline Parameters & $\begin{array}{c}\text { Eryngium } \\
\text { horridum }\end{array}$ & $\begin{array}{c}\text { Eryngium } \\
\text { stenophyllum }\end{array}$ & $\begin{array}{c}\text { Eryngium } \\
\text { aff. serra }\end{array}$ & $\begin{array}{c}\text { Eryngium } \\
\text { elegans }\end{array}$ \\
\hline $\begin{array}{l}\text { No. of plants where chironomid species co-occur/no. of } \\
\text { plants with chironomids (\%) }\end{array}$ & $53 / 66(80.3)$ & $24 / 72(33.3)$ & $41 / 76(53.9)$ & $29 / 68(42.6)$ \\
No. of plants where $P$. parthenogeneticum is dominant. & 49 & 10 & 36 & 15 \\
$\begin{array}{l}\text { No. of plants where } M \text {. eryngiotelmatus is dominant. } \\
\text { No. of plants with similar no. of individuals of both } \\
\quad \text { chironomid species. }\end{array}$ & 4 & 13 & 2 & 14 \\
$\begin{array}{l}\text { Mean no. } \pm \text { standard deviation of individuals of } \\
\text { P. parthenogeneticum when it is dominant. }\end{array}$ & $171.6 \pm 150.2$ & $70.1 \pm 35.1$ & $51.1 \pm 47.279 .5 \pm 92.6$ \\
$\begin{array}{l}\text { Mean no. } \pm \text { standard deviation of individuals of } \\
\text { P. parthenogeneticum when it is not dominant. }\end{array}$ & $15.5 \pm 10.5$ & $9.6 \pm 6.0$ & $2.0 \pm 1.4$ & $8.9 \pm 8.4$ \\
$\begin{array}{l}\text { Mean no. } \pm \text { standard deviation of individuals of } \\
\text { M. eryngiotelmatus when it is dominant. }\end{array}$ & $44.2 \pm 39.8$ & $95.4 \pm 48.3$ & $9.5 \pm 10.6$ & $25.6 \pm 26.5$ \\
$\begin{array}{l}\text { Mean no. } \pm \text { standard deviation of individuals of } \\
\text { M. eryngiotelmatus when it is not dominant. }\end{array}$ & $33.2 \pm 32.4$ & $12.0 \pm 9.1$ & $8.5 \pm 5.9$ & $18.6 \pm 16.9$ \\
\hline
\end{tabular}

\section{Periscelididae}

An unidentified species of Periscelididae of the genus Stenomicra Coquillett was found in the axils of the four species of Eryngium. However, its presence was strongly associated with E. horridum where $99 \%$ of individuals (779/787 immature collected) occurred. No seasonal difference in the individuals' abundance was observed (Table 1), but occurrence of pupae was limited to spring.

\section{Ceratopogonidae}

Two unidentified species of Ceratopogonidae of the genera Dasyhelea and Forcipomyia were collected from Eryngium axils. Forcipomyia had a single individual present in $E$. aff. serra, whereas Dasyhelea sp. occurred in E. aff. serra and E. elegans, and was more abundant in autumn (Table 1). 


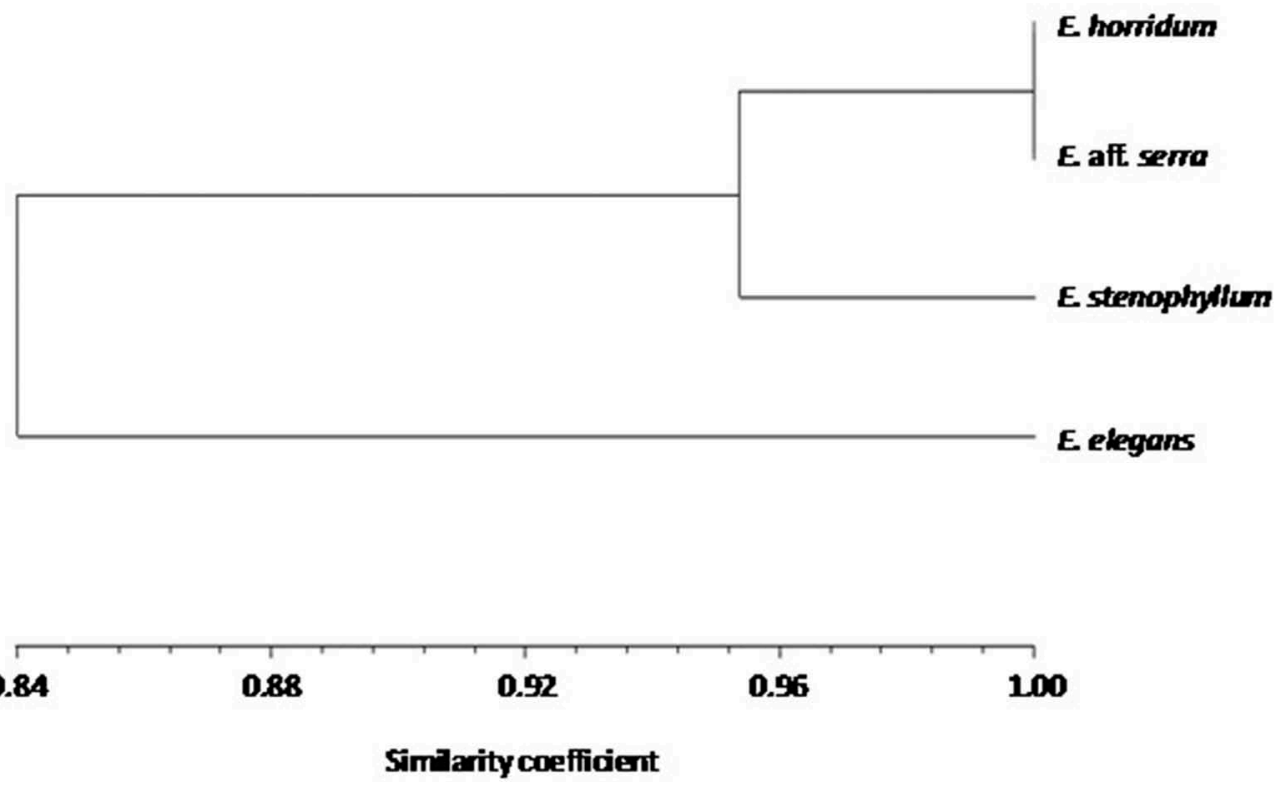

Figure 5. Cluster analysis of the Eryngium phytotelmata in autumn, using the Morisita-Horn index and UPGMA linkage.

\section{Similarity among dipteran communities}

Morisita-Horn indexes of similarity were high for all combinations of species in both autumn and spring. Cluster analysis for the autumn (Figure 5), shows that most differences involved dipteran communities inhabiting E. elegans. Whereas in spring (Figure 6), two groups were defined, one composed of $E$. horridum and $E$. aff. serra, and the second group composed of E. stenophyllum and E. elegans.

\section{Discussion}

\section{Composition of dipterans communities inhabiting Eryngium phytotelmata}

The communities of Diptera associated with the four species of Eryngium consist of saprophages that feed either on the suspended particulate matter, or on small particles that they scrape from package detritus (fine detritus feeders), including chironomids, $M$. eryngiotelmatus and P. partenogeneticum and Culicidae Culex (phytotelmatomyia).

Some syrphid larvae were found in the deepest parts of the axils and could feed by 'scraping' the substrate or the surface of plant leaves. Ceratopogonid larvae (Dasyhelea and Forcipomyia) that could have fed in the detritus (Kitching 2004) were less frequent.

The 'fine detritus feeder' dipterans were dominant in the communities inhabiting phytotelmata of Eryngium.

Among the dipterans inhabiting the axils of Eryngium, only free-swimming predators were recorded. Khoo (1984; cited in Kitching 2004) mentions that the larvae of periscelid Stenomicra are specialized predators in the axils of bromeliads, subsequently Fish (1976) reported that these larvae prey on mosquito larvae Wyomyia spp. Larvae of Stenomicra 


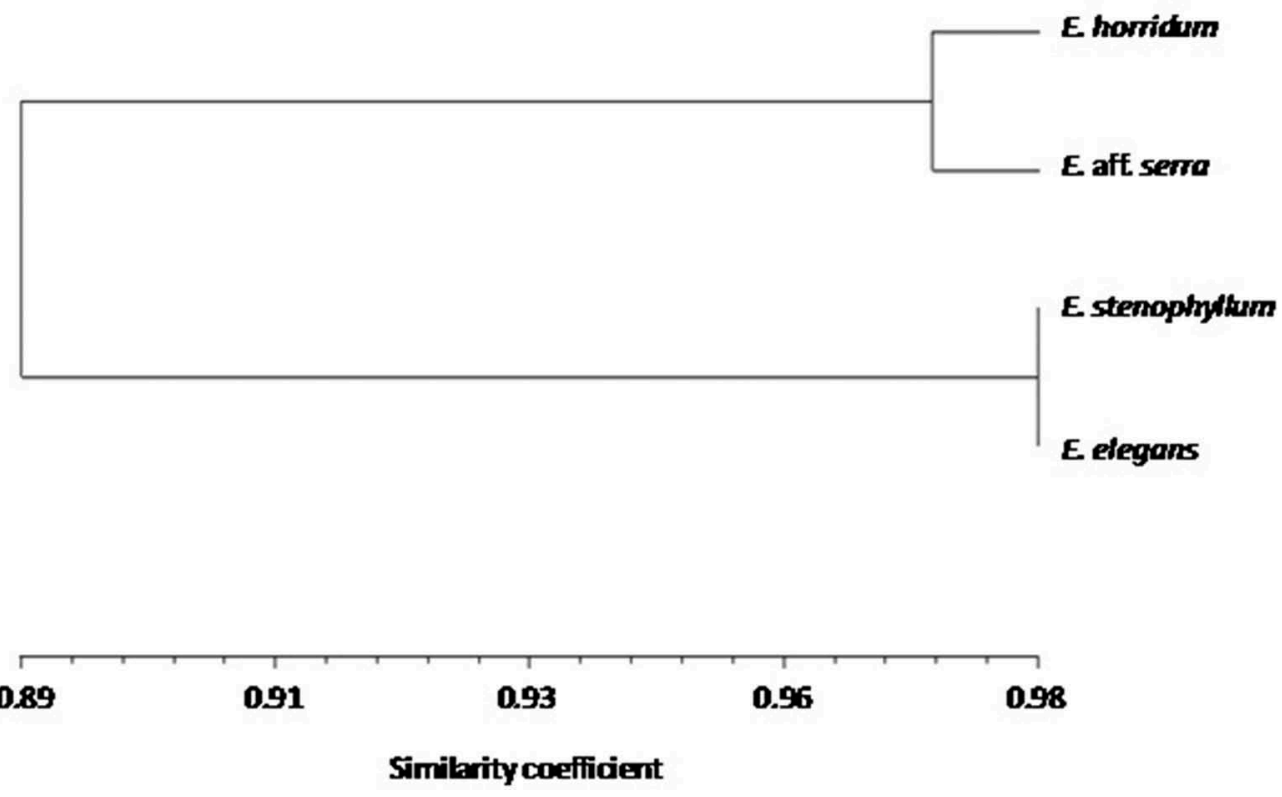

Figure 6. Cluster analysis of the Eryngium phytotelmata in spring, using the Morisita-Horn index and UPGMA linkage.

were abundant in the axils of E. horridum, both in spring and in autumn. Although it was not possible to establish which species were their prey, it could be speculated that early Chironomidae larvae, given their abundance, could form part of their diet.

In the dipteran communities of the other three species of Eryngium studied here, no significant predators were detected. Although Larsia sp. chironomid larvae were found, their predatory action would be limited by their small size, and their scarce abundance, exerting a limited effect on the community.

\section{Relevant families of dipterans of the communities inhabiting Eryngium phytotelmata}

\section{Chironomidae}

Larvae of $M$. eryngiotelmatus and $P$. parthenogeneticum, representing over $87 \%$ of the number of individuals prevailed in the community of dipterans that lived in the axils of Eryngium. Kitching (1971) recorded up to three generations of the chironomid Metriocnemus martinii Thienermann in tree holes, with two population peaks, one in late summer and the other, greater, in autumn. This author considers that hibernation occurs in the larval stage, and the reason for the decrease in the density of the population during that season is mortality, presumably as a result of environmental factors. Although populations of $M$. eryngiotelmatus and $P$. parthenogeneticum inhabiting Eryngium were not sampled in all seasons, it was observed that the population peak also occurred in autumn, doubling the abundance of spring larvae. Furthermore, overlapping generations evidenced by 
overlapping stages, and the presence of pupae in both spring and autumn, suggests that both species are multivoltine in the temperate region of Argentina.

The number of chironomid larvae per plant was highly variable between species and phytotelmata. This variation was more noticeable for $P$. parthenogeneticum than for $M$. eryngiotelmatus, and although this pattern was observed in the four species of Eryngium, it was more evident in E. horridum.

Kitching (1972), in a study on oviposition of M. martinii reported an average of 51.3 eggs per clutch with a wide range around the mean, without observing seasonal variation. So far, the biology of $M$. eryngiotelmatus oviposition is not known, but according to observations in the laboratory, $P$. parthenogeneticum reproduces by parthenogenesis and females oviposit between 12 and 24 hours after the emergence of the imago, each female producing more than three batches containing between 37 and 123 eggs per clutch (Donato and Paggi 2008). That reproductive potential, coupled with several females ovipositing simultaneously, explain the high number of larvae observed in some plants. Larvae observed in plants with an abundant number of individuals, mostly corresponded to early stages, while in plants with fewer individuals late larvae and pupae predominated. This variation in the number of larvae, could show that the higher incidence of mortality factors could be acting on the early stages of both chironomids.

In several studies, the coexistence of chironomid species in other than Eryngium phytotelmata is mentioned. Picado (1913) described Metriocnemus abdominoflavatus and Chirocladius pedipalpus living in axils of tank bromeliads in Costa Rica, and Miller (1971) in a study of two species of bromeliads in the U.S. Virgin Islands, mentions the co-existence of three species of the genera Tanytarsus, Pentaneura and Metriocnemus, the latter being the least abundant. Moreover, Beaver (1983) observed species of the genera Metriocnemus and Polypedilum breeding in the pitcher plant Nepenthes villosa in Borneo, and in plants of the same species introduced to Britain from Sabah (cited in Cranston and Judd 1987). The co-occurrence of M. eryngiotelmatus and P. parthenogeneticum in Eryngium was reported by Donato and Paggi (2008). The ecological association between these two species was studied using the association coefficient $C_{8}$ species, estimated for four species of Eryngium but significant only for E. horridum (Campos 2010). The present study shows that the co-existence of both species occurs in the four species of Eryngium, being higher in E. horridum, where both chironomids were present in $80 \%$ of the plants examined. Polypedilum parthenogeneticum was dominant in three of the four phytotelmata (see Table 5), however the number of individuals in the plants where only this species was found, was lower compared with that of $M$. eryngiotelmatus when this species was in the same situation. These observations require specific laboratory studies to distinguish between the effects of intra- and inter-specific competition.

The high reproductive potential of $P$. parthenogeneticum and the similarity in the pattern of abundance in the four species of Eryngium, could indicate a better fitness for this species than for M. eryngiotelmatus, particularly when inhabiting the same plant.

\section{Culicidae}

The family Culicidae has been cited as one of the main inhabitants of phytotelmata, both in species diversity and in numerical abundance (Fish 1983). Three species of Culex 
(Phytotelmatomyia) and an undetermined species inhabiting the axils of Eryngium spp. are known in the temperate zone of Argentina (Campos and Lounibos 1999; Albicócco et al. 2011) above the parallel $34^{\circ} 51^{\prime} 33^{\prime \prime} S$. South of this latitude, in Sierra de la Ventana, two species of mosquitoes, C. castroi and C. renatoi were found (Campos 2010), but their abundance was low, with E. horridum phytotelmata the best host to both species. In the present study, both species were found in E. horridum, but only C. renatoi was found in the other species of Eryngium. Its population was abundant in E. horridum, with a notable increase in the spring. In this study, $C$. castroi was more abundant in autumn than in spring, whereas C. renatoi showed an inverse pattern. However, in both seasons, $C$. renatoi was much more abundant than C. castroi. In a previous study (Campos and Lounibos 1999), where the occurrence of these two species of mosquitoes in E. cabrerae Pontiroli was analysed, a predominance of $C$. renatoi with respect to $C$. castroi was also observed.

\section{Periscelididae}

Larvae of Stenomicra were recently reported in Argentina, breeding in Eryngium spp. with a marked seasonality of pupation, which occurs in October and is produced on the leaves out of the water (Campos et al. 2010). In the present study, the same seasonal pattern was observed, suggesting that in the temperate zone of Argentina, Stenomicra sp. is univoltine, with a long life cycle and hibernation in the larval stage.

\section{Ceratopogonidae}

Three species of ceratopogonids are known to breed in Eryngium phytotelmata, Culicoides charruus Spinelli and Martinez, and two undetermined species of the genera Dasyhelea and Forcipomyia (Campos 2010, Appendix.). Culicoides charruus, whose larvae were recorded from axils of E. serra (Spinelli and Martínez 1991) and E. pandanifolium Cham. and Schlecht (Ronderos et al. 2008), was not found in the species of Eryngium of Sierra de la Ventana. More than 20 species of Dasyhelea, breeding in pitcher plants, tree holes, water axils and bamboo internodes, are known (Kitching 2004). An undetermined species of Dasyhelea was the dominant ceratopogonid in E. aff. serra and E. elegans and was more abundant in autumn than in spring, but it was not recorded in E. horridum or in E. stenophyllum.

\section{Similarity among dipteran communities}

Both clusters show that dipteran communities inhabiting E. horridum and E. aff. serra are similar, whereas the communities of dipterans inhabiting E. stenophyllum and E. elegans differ from the first in both autumn and spring. High values of the similarity coefficients indicate that the four phytotelmata provide a suitable habitat for all taxa of the dipteran communities. However, the strong similarity between communities could be attributed to the high sensitivity of the coefficient to the dominant species, being influenced by the abundance of Chironomidae.

\section{Conclusion}

It is concluded that the four sympatric Eryngium spp. are used by Diptera differently and their populations show seasonal changes, with peaks in autumn. The communities of dipterans that live in the axils of the four Eryngium species are composed of larvae 
belonging to six aquatic and seven semi-aquatic families. The main families are Chironomidae, Culicidae, Periscelididae and Ceratopogonidae. Two species of Chironomids ( $M$. eryngiotelmatus and $P$. polypedilum) were the most abundant in all Eryngium species in both autumn and spring. Species of Culicidae, Periscelididae and Ceratopogonidae were more selective than Chironomidae. The first two families were best represented in the community of E. horridum, whereas Ceratopogonidae were found in $E$. aff. serra and $E$. elegans. The seasonal presence of the families of dipterans was different between Eryngium species. Major diversity was recorded from all Eryngium in the autumn, except for E. stenophyllum. Saprophages were the most abundant in the communities, with the fine detritus feeders being the dominant group. The periscelid Stenomicra was the most important free-swimming predator (abundant in E. horridum and scarce in the others species of Eryngium). No top predators were recorded in the four Eryngium phytotelmata.

\section{Acknowledgements}

I would like to thank the following for taxonomic determination of specimens: Susana Martínez (Apiaceae) (Facultad de Ciencias Exactas y Naturales, Universidad de Buenos Aires); Analía Paggi and Augusto Siri (Chironomidae) (ILPLA, UNLP); Gustavo Spinelli (Ceratopogonidae) (Facultad de Ciencias Naturales y Museo, Universidad Nacional de La Plata), and Augusto Siri for critical review, and Mrs Monica Caviglia for review of the English. I also thank the authorities of the 'Ernesto Tornquist' Provincial Park for the logistics to conduct this study. The project was evaluated by the committee for the Management of Protected Areas and Conservation of Diversity belonging to the Provincial Agency for Sustainable Development (OPDS, Spanish initials). This agency approved the methodology and granted the corresponding permission to develop the studies. The author is a member of the National Research Council of Argentina, CONICET. This research was supported by PIP 5924, CONICET, Argentina. This is a contribution of the Instituto de Limnología Journal Series No 945.

\section{Disclosure statement}

No potential conflict of interest was reported by the author.

\section{References}

Albicócco AP, Carbajo AE, Vezzani D. 2011. Mosquito community structure in phytotelmata from a South American temperate wetland. J Vect Ecol. 36:437-446.

Balseiro EG. 1983. Observaciones sobre la selectividad de áreas de postura en una población local de Culex castroi Casal y García (Diptera, Culicidae). Rev Soc Entomol Argent. 42:125-130.

Beaver RA. 1983. The communities living in Nepenthes pitcher plants: fauna and food webs. In: Frank JH, Lounibos LP, editors. Phytotelmata: terrestrial plants as hosts of aquatic insect communities. Medford (NJ): Plexus Inc.

Burgos JJ, Vidal AL. 1951. Los climas de la república Argentina según la nueva clasificación de Thornthwaite. Meteoros. 1:3-32.

Cabrera AL, Willink A. 1980. Biogeografía de América Latina [Biogeography of Latin America]. Washington, DC: Serie de Biología, Monografía 13. Organization of American States.

Campos RE. 2010. Eryngium (Apiaceae) phytotelmata and their macro-invertebrates communities, including a review and bibliography (with appendix). Hydrobiologia. 652:311-328. 
Campos RE, Fernández LA. 2011. Coleopterans associated with plants that form phytotelmata in subtropical and temperate Argentina, South America. J Insect Sci. 11:1-18.

Campos RE, Gramajo MC, Lizarralde de Grosso M. 2010. Stenomicra (Diptera: Opomyzoidea) in Argentina, with information on the biology of the genus. Rev Soc Entomol Argent. 69:281-285.

Campos RE, Lounibos LP. 1999. Eryngium spp. (Umbelliferae) as phytotelmata and their Culex (Culex) inhabitants in temperate Argentina. J Am Mosq Contr Assoc. 15:493-499.

Cranston PS, Judd DD. 1987. Metriocnemus (Diptera: Chironomidae). An ecological survey and description of a new species. J N Y Entomol Soc. 95:534-546.

Donato M, Paggi AC. 2008. Polypedilum parthenogeneticum (Diptera: Chironomidae): a new parthenogenetic species from Eryngium L. (Apiaceae) phytotelmata. Aquatic Insects. 30:51-60.

Fish D. 1976. Insect-plant relationships of the insectivorous pitcher-plant Sarracenia minor. Fla Entomol. 59:199-203.

Fish D. 1983. Phytotelmata: flora and fauna. In: Frank JH, Lounibos LP, editors. Phytotelmata: terrestrial plants as hosts of aquatic insect communities. Medford (NJ): Plexus Inc.; p. 1-27.

Franigi JL, Bottino OJ. 1995. Comunidades vegetales de la Sierra de la Ventana, provincia de Buenos Aires, Argentina. Rev Fac Agr La Plata. 71 (1):93-133.

Frank JH, Lounibos LP. 1983. Phytotelmata: terrestrial plants as hosts of aquatic insects communities. Medford (NJ): Plexus Inc.

Harrington H. 1947. Explicación de las hojas 33m y 34m: Sierra de Curamalal y Ventana, Provincia de Buenos Aires. Dir M Geol Bs As Bol. 51:1.

Khoo KC. 1984. The Australian species of Cyamops Melander (Diptera: Periscelidae). Aust J Zool. 32:527-536.

Kitching RL. 1971. An ecological study of water-filled tree-holes and their position in the woodland ecosystem. J An Ecol. 40:281-302.

Kitching RL. 1972. Population studies of the immature stages of the tree-hole midge Metriocnemus martini Thienemann (Diptera: Chironomidae). J An Ecol. 41:53-62.

Kitching RL. 2004. Food webs and container habitats: the natural history and ecology of phytotelmata. Cambridge: Cambridge University Press.

Kristensen MJ, Frangi JL. 1995. Mesoclimas de pastizales de la Sierra de la Ventana. Ecol Aust. 5:55-64.

Machado ABM. 1976. Fauna associada a água das folhas de umbelíferas com observações sobre a ninfa de Roppaneura beckeri Santos (Odonata-Protoneuridae). Ciên Cult. 28:895-896.

Magurran A. 1988. BIO-DAP - Ecological diversity and its measurement. Alma, New Brunswick: Fundy National Park.

Martínez S. 2005. Flora Fanerogámica Argentina, Fasc. 94. 228. Apiaceae, parte 2. Subfamilia III. Saniculoideae. Buenos Aires, Argentina: Programa Proflora, CONICET.

Micieli MV, Marti GA, García JJ, Tranchida MC, Becnel JJ. 2007. Epizootiological studies of Amblyospora camposi (Microsporidia: Amblyosporidae) in Culex renatoi (Diptera: Culicidae) and Paracyclops fimbriatus fimbriatus (Copepoda: Cyclopidae) in a bromeliad hábitat. J Inv Path. 94:31-37.

Miller AC. 1971. Observations on the Chironomidae (Diptera) inhabiting the leaf axils of two species of Bromeliaceae on St. John, U. S. Virgin Islands. Can Entomol. 103:391-396.

Nugues MM, Bak RPM. 2006. 'Differential competitive abilities between Caribbean coral species and a brown alga: a year of experiments and a long-term perspective'. Mar Ecol Prog Ser. 315:75-86.

Picado C. 1913. Les bromeliacées epiphytes, considérées comme une milieu biologique. Bull Sci Fr Belg (Série 7). 47:215-360.

Ronderos MM, Spinelli GR, Borkent A. 2008. A description of the larva and pupa of Culicoides charruus Spinelli and Martínez (Diptera: Ceratopogonidae) from leaf axils of Eryngium pandanifolium (Apiaceae) in Argentina. J Russ Entomol. 17:155-122.

Scheirer C, Ray W, Hare N. 1976. The analysis of ranked data derived from completely randomized factorial designs. Biometrics. 32:429-434. 
Siri A, Marti GA, López Lastra CC. 2008. Prevalence of Harpellales from Chironomidae larvae in phytotelmata from Punta Lara Forest, Argentina. Mycologia. 100:381-386.

SMN. 1981. Estadísticas climatológicas. 1961-1970 [Internet]. Fuerza Aérea Argentina: Servicio Meteorológico Naciona. [cited 2010 Feb 15]. Available from: http://www.smn.gov.ar

SMN. 1986. Estadísticas climatológicas. 1971-1980 [Internet]. Fuerza Aérea Argentina: Servicio Meteorológico Nacional. [cited 2010 Feb 15]. Available from: http://www.smn.gov.ar

Sokal RR, Rohlf FJ. 1995. Biometry. New York (NY): W. H. Freeman and Co.

Spinelli GR, Martínez ME. 1991. The genus Culicoides in Uruguay (Diptera: Ceratopogonidae). Insecta Mundi. 5:175-180.

Stehr FW, editor. 1991. Immature insects, Vol. 2. lowa (USA): Kendall and Hunt Publ. Co.

Vucetich MC, Rossi JB. 1980. Estudio preliminar de la fauna fitotélmica de Eryngium pandanifolium Cham. et Schlecht. Limnobios. 1:403-409.

Wolda H. 1981. Similarity índices, sample size and diversity. Oecologia. 50:296-302. 